Article

\title{
Effects of the Mortar Matrix on the Flexural Capacity of Masonry Cross Sections Strengthened with FRCM Materials
}

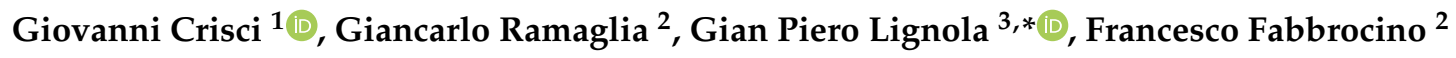 \\ and Andrea Prota ${ }^{3}$ \\ 1 Department of Engineering, University of Naples "Parthenope", Centro Direzionale C4, 80143 Naples, Italy; \\ giovanni.crisci@uniparthenope.it \\ 2 Department of Engineering, Telematic University Pegaso, Piazza Trieste e Trento, 48, 80132 Naples, Italy; \\ giancarlo.ramaglia@unipegaso.it (G.R.); francesco.fabbrocino@unipegaso.it (F.F.) \\ 3 Department of Structures for Engineering and Architecture, University of Naples Federico II, Via Claudio 21, \\ 80125 Naples, Italy; aprota@unina.it \\ * Correspondence: glignola@unina.it; Tel.: +39-081-768-3492
}

Received: 7 October 2020; Accepted: 4 November 2020; Published: 8 November 2020

\begin{abstract}
The strengthening intervention strategies that exist for masonry buildings are based on the use of thin composites and are a recent activity used in structural engineering. Nowadays, mortar matrices are frequently found instead of epoxy resins, since the fiber reinforced cementitious matrix (FRCM) composites are more compatible with masonry than fiber reinforced plastic (FRP) ones. The mortar matrix in FRCM composites is not comparable to the epoxy resin, and therefore its contribution is different not only in traction but above all on the compression side. Due to its larger thickness, if compared to the epoxy resin, the impact of the mortar matrix on the flexural response of strengthened cross sections is not negligible. This paper aimed to investigate the influence of the contribution of the mortar matrix on the compression side on the flexural capacity of strengthened cross section. As such, $\mathrm{p}-\mathrm{m}$ interaction domains and bending moment-curvature diagrams were evaluated to understand the influence of several mechanical properties of fiber and mortar matrices on FRCM efficiency, typical of real applications. Hence, the impact of several constitutive relationships of composites (linear and bilinear behavior) was considered for the structural analysis of the strengthened cross section. The presented results are all completely in a dimensionless form; therefore, independent of geometry and mechanical parameters can be the basis for developing standardized design and/or verification methodologies useful for the strengthening systems for masonry elements.
\end{abstract}

Keywords: masonry; FRCM; mortar matrix in compression; out-of-plane

\section{Introduction}

Nowadays, the use of composites for strengthening intervention and structural rehabilitation of existing masonry buildings is of paramount importance. The last seismic events in Italy, such as L'Aquila (2009), Emilia Romagna (2012), Central Italy (2016), and Ischia (2017), have confirmed the high vulnerability of masonry structures [1-3]. This is a crucial point for the Italian regions, where the masonry buildings represent the large part of the existing stock (i.e., churches, historic monuments, residential buildings). Such structures were built according to inadequate codes without seismic criteria. The need to retrofit these buildings today is clearer than before [4-6]. In the last few years, new techniques based on the use of fiber reinforced composite materials-i.e., fiber reinforced plastics (FRP) and fiber reinforced cementitious matrix (FRCM) - were developed and studied. The first ones 
are based on the use of high strength fibers bonded by means of epoxy resin and applied on concrete, steel, masonry, and wooden structural element [7-11]. Pre-formed FRP materials are largely used as well, made of fibers pre-impregnated with resins in the form of a sheet, characterized by initial axial rigidity, and a mono-directional behavior [12] that can be mechanically fastened [13]. These composites could represent the best solution for structural rehabilitation; indeed, they are characterized by a high strength/weight ratio, being successful in increasing the flexural capacity for the structural element without significant increases of mass of structures. For masonry buildings, the use of a mortar matrix (i.e., FRCM) instead of an organic one (i.e., FRP) is preferred. Indeed, cementitious matrices offer better performance under elevated temperatures and better compatibility with modern masonry substrates. In fact, several authors observed good performances in practical applications [14-19]. More studies, however, are required to better understand the behavior of composite material on the structural response of strengthened masonry elements [20-22], both in terms of flexural [23-25] and shear performance [26-28].

The calculation models proposed by Italian guidelines CNR-DT 215 [29] and/or internationals codes provide good results for FRP where the contribution of the mortar matrix can be completely neglected. Such assumptions cannot be directly extended to the case of FRCM. Indeed, FRCM, which is also referred to as TRM, i.e., textile reinforced mortar, is composed of a fiber grid with a thickness similar to FRP dry fibers, which is embedded in a mortar matrix with a thickness of about 10-20 mm, i.e., about one order of magnitude higher than FRP organic matrix.

A strengthening system is applied, generally, on the side where the masonry is weaker by its nature, i.e., on the tensile side. Due to the force reversal during seismic actions, the application of reinforcement systems occur on both sides of a masonry panel. Current Italian guidelines [29] not only neglect the contribution of the mortar matrix (on tensile side), leading to FRCM being conflated with FRP, but they disregard the strengthened layer on a compression side, assuming that the composite material is unable to carry loads.

This paper aimed to analyze the impact of the mortar matrix on the flexural capacity of the strengthened cross section (see Figure 1), observing the dimensionless axial load (p) and bending moment (m) interaction domains [30], as well as the ductility capacity through the analysis of the bending moment-curvature diagrams. The results are shown in a dimensionless form. Since they are independent geometrical and mechanical parameters of the masonry and strengthening system, they could represent the basis for the development of design and verification approaches.

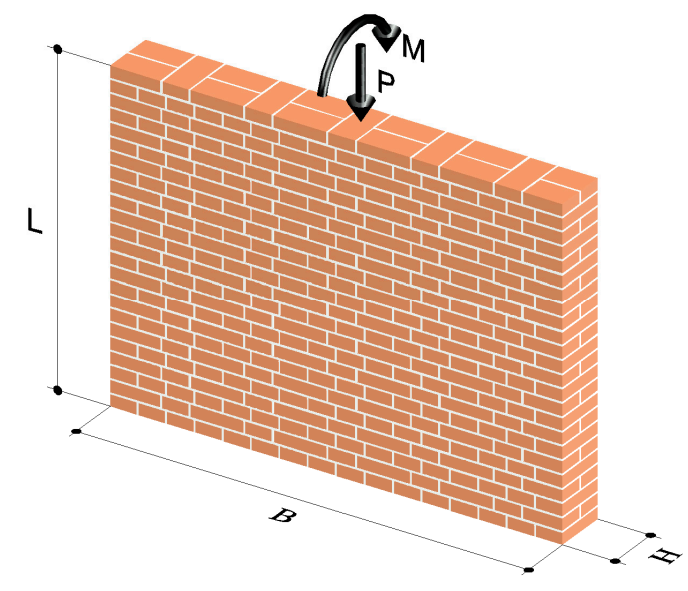

(a)

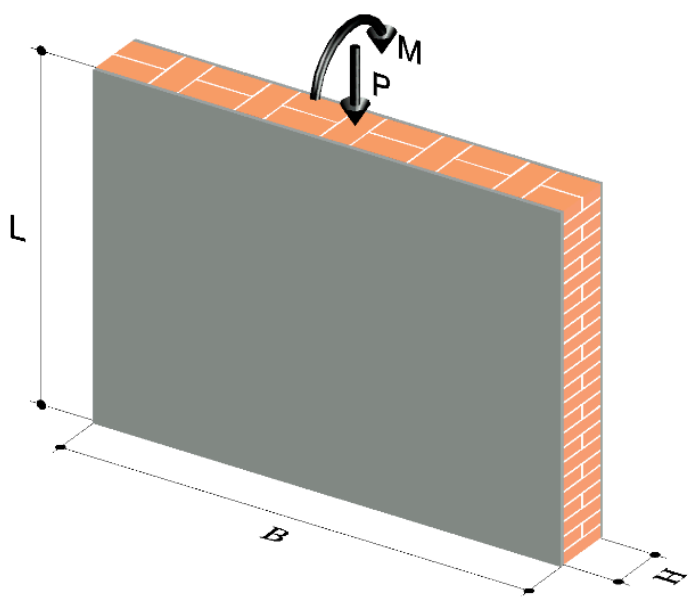

(b)

Figure 1. (a) Unreinforced masonry panel; (b) strengthened masonry panel with fiber reinforced cementitious matrix (FRCM) composite. 


\section{Materials and Methods}

In this section, the constitutive law of the materials (such as masonry and FRCM) adopted for the structural analysis are defined. From the scientific literature, several stress-strain constitutive relationships can be used to describe the mechanical behavior of masonry [31]. One of the most adopted models for compressive behavior, used for the presented analyses, is suggested by CEN Eurocode 6 [32], as shown in Figure 2. This model completely neglects the post-peak softening, considering a perfectly plastic post-peak behavior. The tensile behavior, on the other hand, can be described by elastic-brittle relationship, yet for the purposes of the present work, its contribution is negligible when the strengthening system is applied.

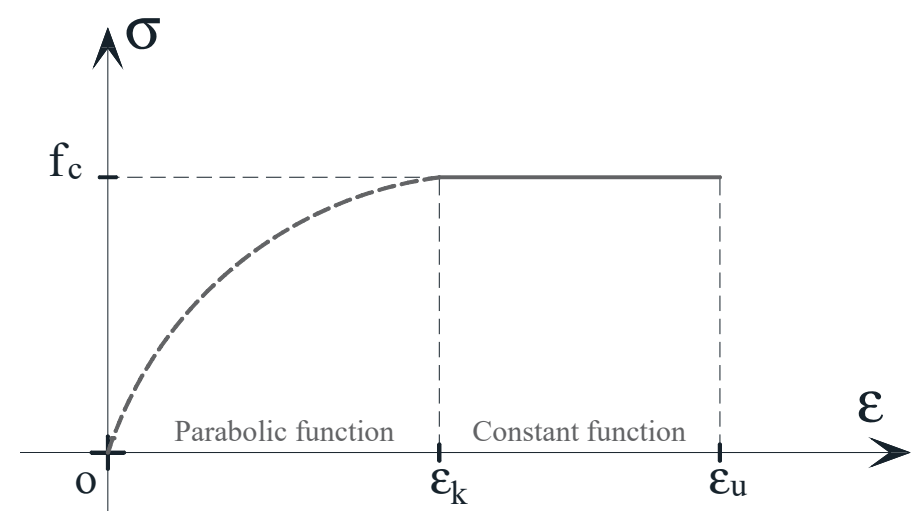

Figure 2. Stress-strain relationships of the masonry.

Composite materials are, by definition, made up of two or more materials known as phases. In FRCM composite materials, it is possible to differentiate exactly three phases: the fibrous phase, the mortar matrix phase, and the interface phase. Due to this mixed nature of the mortar matrix and fiber, the FRCM composite is characterized by various phenomena such as matrix cracking, slip, or debonding phenomena. However, it is possible to provide a general stress-strain relationship to simulate the behavior of the whole composite system to interpret the different factors that influence its behavior most. De Felice et al. [33] reported three different stress-strain relationships to simulate the behavior of composite systems in tension: linear, bilinear, and trilinear behavior. For the purposes of this work, only the linear and bilinear behaviors were compared to different behaviors between a classical FRP and FRCM with synthetic fibers, as shown in Figure 3. Moreover, the bilinear and trilinear relationships take into account several effects of the mortar matrix, such as the cracking, bond slip, or tension stiffening effect that are neglected by the linear behavior.

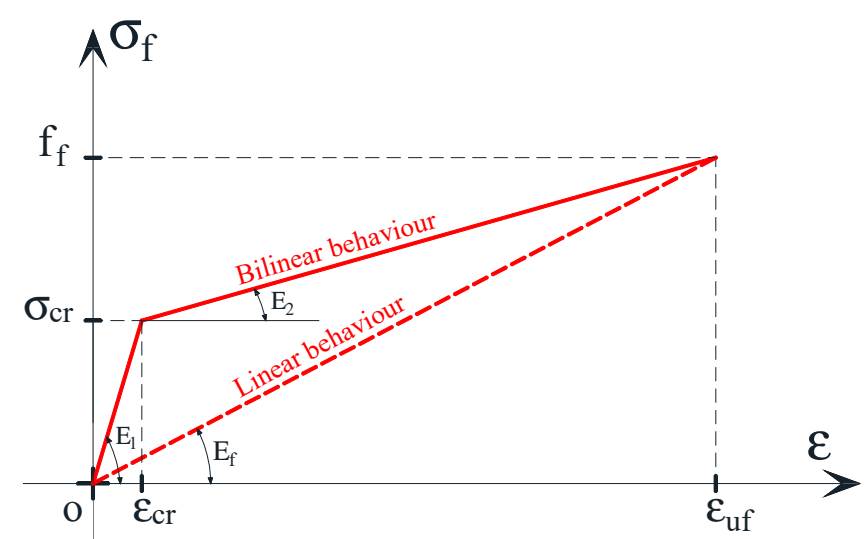

Figure 3. Different stress-strain constitutive relationships for composite systems in tension. 
The structural analysis of the strengthened cross section was performed with reference to the $\mathrm{p}-\mathrm{m}$ interaction domains that allows for the evaluation of the flexural capacity $(\mathrm{m})$ under a specified axial load (p) in the dimensionless format. Indeed, we evaluated the impact of mechanical parameters on the flexural capacity response. The numerical analysis of the cross section is based on the same classic assumptions used for reinforced concrete (RC) cross sections in the technical approach.

- Conservation of plain sections (also referred to as the Bernoulli-Navier assumption);

- validity of the Bernoulli principle, wherein the shear deformability is neglected;

- the stress-strain relationship of the materials is known a priori;

- the stresses are dependent on the strain of the element alone, so that the effects of viscosity and shrinkage over time are neglected;

- it is assumed that the application of the load and consequent deformation take place in a monotonous way, and thus they do not explicitly consider the behavior under cyclic loads;

- it assumes the perfect bond between masonry and the strengthening system (without slip);

- the ultimate condition of the cross section is reached, either by crushing the compressed masonry or tensile failure of the composite system.

As listed previously, the strengthening system was considered perfectly bonded to the masonry substrate in accordance to several experimental bond tests [34,35], which evidenced that debonding phenomena from the substrate rarely occur for such materials. Bonding with the matrix fiber interface is included in the phenomenological constitutive relationships in tension for the composites.

The construction of $\mathrm{p}-\mathrm{m}$ interaction domains has considered with a completely dimensionless form. To better understand the dimensionless procedure, we started from translation and rotation equilibrium equations wherein each contribution is in dimensional form. Per usual, from the latter equations, the depth of the neutral axis and the flexural capacity of the strengthened cross section can be defined, as Equations (1) and (2) report:

$$
\begin{gathered}
P=\psi \cdot x \cdot B \cdot f_{c}-B \cdot t_{f} \cdot \sigma_{f}+B \cdot t_{m o r} \cdot \sigma_{m o r} \\
M=\psi \cdot x \cdot B \cdot f_{c} \cdot\left(b_{c}\right)+B \cdot t_{f} \cdot \sigma_{f} \cdot\left(b_{f}\right)+B \cdot t_{m o r} \cdot \sigma_{m o r} \cdot\left(b_{m o r}\right)
\end{gathered}
$$

According to Figure 4:

- $\quad P$ and $M$ are the axial force and the bending moment;

- $f_{c}$ is the compressive strength of masonry;

- $\sigma_{m o r}$ and $\sigma_{f}$ are the stress of the mortar matrix on compression side (same relationship of masonry, see Figure 2) and the stress of the composite on tension side, respectively;

- $\quad B$ and $H$ are the base and the height of the cross section, respectively;

- $t_{f}, t_{m o r}$ are the thickness of fibers and mortar matrix, respectively;

- $b_{c}, b_{f}$ and $b_{m o r}$ are the distances of force resultants from the centroid of cross section, respectively.

The fundamental quantities for the structural analysis of a strengthened cross section were evaluated as dimensionless. Given a generic masonry cross section, the main dimensionless parameters are [23]:

$$
p=\frac{P}{B \cdot H \cdot f_{c}} m=\frac{6 \cdot M}{B \cdot H \cdot f_{c}}
$$

With regard to the strengthening system, different dimensionless procedures were performed for the tensile and compressive sides. In Ramaglia et al. [23], a detailed procedure was presented for the composite material on each tensile side (in red in Figure 4), where its contribution is normalized with reference to its ultimate tensile strength. Conversely, this study presents how the compressive contribution offered by the mortar matrix (in blue in Figure 4) can be normalized. Indeed, it was performed with reference to the ultimate compressive strength of the mortar matrix. 


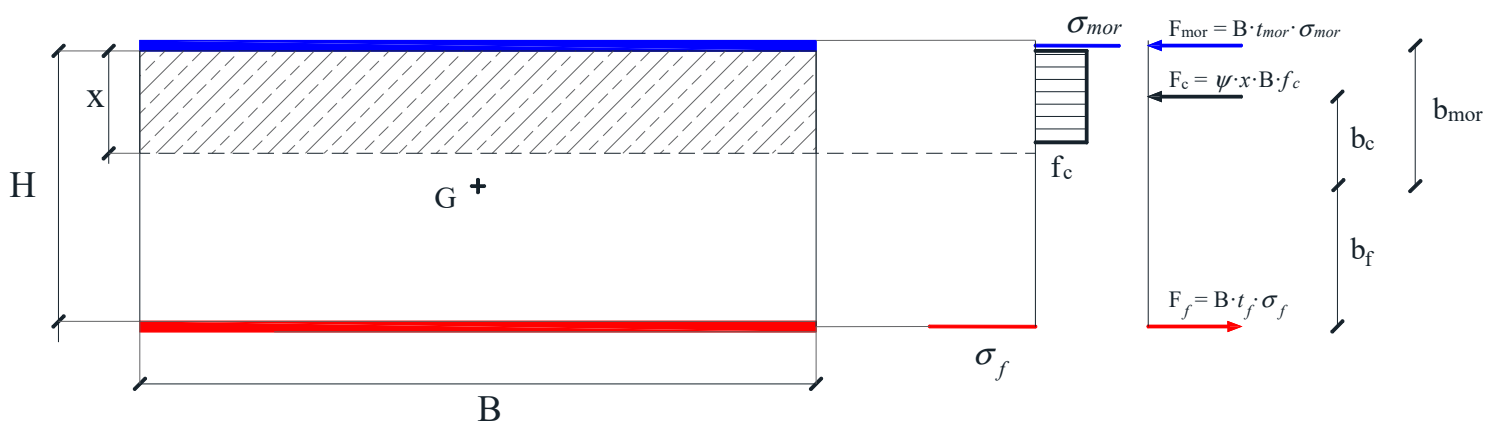

Figure 4. Equilibrium of strengthened masonry section including the effect of mortar matrix of the composite in compression-dimensional form.

The constitutive relationship of the mortar matrix adopted for numerical analysis was the same as of concrete, i.e., the parabola-rectangle diagram [36]. The behavior of the mortar matrix under compression loads was not far from the concrete loads. The contribution of compressed fibers was neglected, as is usually done for FRP strengthening systems due to their slenderness and low mechanical contribution compared to the mortar matrix in compression.

Manipulating Equations (1) and (2) shows the translation and rotation equilibrium equations of the strengthened cross section, respectively:

$$
\begin{gathered}
P=\psi \cdot x \cdot B \cdot f_{c}-A_{f} \cdot \sigma_{f}+A_{\text {mor }} \cdot \sigma_{\text {mor }} \\
M=\psi \cdot x \cdot B \cdot f_{c} \cdot\left(b_{c}\right)+A_{f} \cdot \sigma_{f} \cdot\left(b_{f}\right)+A_{\text {mor }} \cdot \sigma_{\text {mor }} \cdot\left(b_{\text {mor }}\right)
\end{gathered}
$$

According to (3), the Equations (4) and (5) can be written in dimensionless form:

$$
\begin{gathered}
p=\psi \cdot \xi-\omega_{f} \cdot \overline{\sigma_{f}}+\omega_{m} \cdot \overline{\sigma_{m}} \\
m=\psi \cdot \xi \cdot(3-6 \cdot \lambda \cdot \xi)+\left(\omega_{f} \cdot \overline{\sigma_{f}}+\omega_{m} \cdot \overline{\sigma_{m}}\right) \cdot\left(3+3 \cdot \rho_{m}\right)
\end{gathered}
$$

where (see Figure 5):

- $\quad \xi$ is the depth of neutral axis normalized with reference to cross section height, $\xi=x / H$;

- $\psi$ and $\lambda$ are the coefficients (dimensionless) that correlate to the real non-linear stress distribution to the uniform distribution and the distance of the resultant of real non-linear stress distribution to the neutral axis depth, respectively [37];

- $\quad \omega_{f}$ and $\omega_{m}$ are the mechanical fiber reinforcement ratios related to the tensile and the compressive sides respectively, defined as:

$$
\omega_{f}=\frac{A_{f} \cdot f_{f}}{B \cdot H \cdot f_{c}} \omega_{m o r}=\frac{A_{\text {mor }} \cdot f_{\text {mor }}}{B \cdot H \cdot f_{c}}
$$

where $A_{f}$ and $A_{\text {mor }}$ are the cross section of dry fiber and of mortar matrix respectively, while $f_{\text {mor }}$ and $f_{f}$ are the strength of mortar matrix (in compression) and of composite (in tension);

- $\quad \rho_{m}$ is the ratio between the thickness of the mortar and the height of masonry cross section:

$$
\rho_{m}=\frac{t_{m o r}}{H}
$$

- $\bar{\sigma}_{m}$ and $\bar{\sigma}_{f}$ are the stress of the mortar matrix on the compression side and the stress of the composite on the tensile side, normalized with reference to the compressive strength of the mortar matrix and to the tensile strength of composite, respectively; 


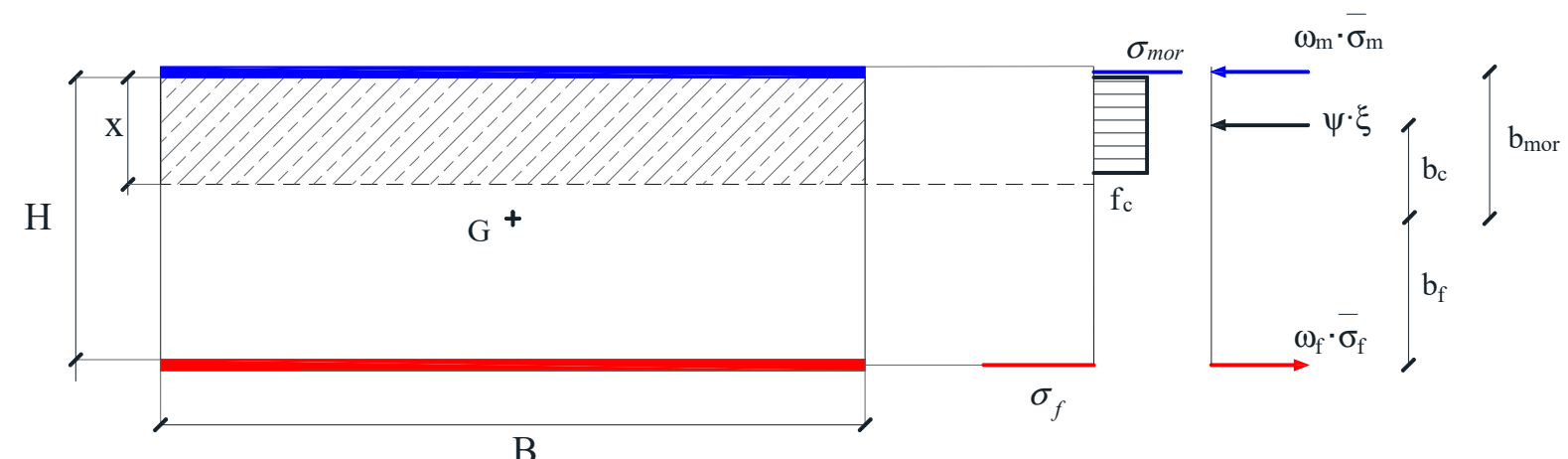

Figure 5. Equilibrium of the strengthened masonry section including the effect of the mortar matrix of the composite in compression-dimensionless form.

The effect of the mortar matrix on the flexural capacity of the strengthened cross section was analyzed in terms of flexural capacity through the $\mathrm{p}-\mathrm{m}$ interaction domains, considering the influence of different stress-strain relationships of the composite material, as well as observing, at the same time, the structural behavior of the cross section with, or without, the contribution of the compressed mortar matrix.

It is very important, for the safety of the structures after exceptional actions such as earthquakes, to look over the capacity of the structural elements and include post elastic behavior in evaluations. In this way, the structures can exploit their own capacity to dissipate energy produced during earthquakes in a controlled manner and in specific zones of the structures, expressing the desired collapse mode. It is necessary that structures have an adequate "ductility". As a result, bending moment-curvature diagrams have been developed, highlighting how the ultimate curvature changes as the constitutive relationship of the FRCM composite and the contribution in compression of the mortar matrix varies.

The analyses have been carried out on four different cases in order to highlight, on a purely theoretical basis, the comparison between several strengthening systems. In particular:

(1) The linear relationship on the tension side and no mortar contribution on the compression side;

(2) The bilinear relationship on the tension side and no mortar contribution on the compression side;

(3) The linear relationship on the tension side and no mortar contribution on the compression side;

(4) The bilinear relationship on the tension side and mortar contribution on the compression side.

In Ramaglia et al. [23], the typical ranges of variation of the individual materials composing a FRCM composite have been identified. As a result, the dimensionless parameters adopted for the analysis have been chosen, which defined two constitutive relationships to strengthen the system. Listed in Table 1, they are as follows:

- $\bar{E}_{f}$ is the normalized modulus of elasticity of the dry fiber $\left(E_{f} / f_{f}\right)$;

- $\bar{E}_{1}$ is the normalized uncracked modulus of elasticity of the composite $\left(E_{1} / f_{f}\right)$;

- $\bar{E}_{2}$ is the normalized post-cracking modulus of the composite $\left(E_{2} / f_{f}\right)$;

- $\bar{\sigma}_{c r}$ is the normalized first cracking strength of the mortar matrix;

- $\varepsilon_{u f}$ is the ultimate strain of composite.

Table 1. Normalized parameters adopted for the analyses.

\begin{tabular}{ccccc}
\hline $\bar{E}_{f}$ & $\bar{E}_{1}$ & $\bar{E}_{2}$ & $\bar{\sigma}_{c r}$ & $\varepsilon_{u f}$ \\
\hline$[-]$ & {$[-]$} & {$[-]$} & {$[-]$} & {$[-]$} \\
\hline 16.67 & 500 & 12.61 & 0.25 & 0.06 \\
\hline
\end{tabular}

The outcomes of the research by Ramaglia et al. [23] allowed us to focus on typical ranges of material properties and, as an example, the properties of a commercial system are adopted and 
normalized. In Table 1, the normalized parameters are derived from a material, with the mechanical properties outlined in Table 2:

- $E_{m}$ is the modulus of elasticity of the mortar matrix;

- $\sigma_{c r}$ is the homogenized first cracking in tension of the mortar matrix [23];

- $E_{f}$ is the modulus of elasticity of the dry fiber;

- $E_{1}$ is the uncracked modulus of elasticity of the composite homogenized to dry fiber [23] (see Figure 3);

- $\quad E_{2}$ is the post-uncracked modulus of elasticity of the composite homogenized to the dry fiber [23] (see Figure 3);

- $\varepsilon_{c r}$ is the strain corresponding to the stress $\sigma_{c r}$.

Table 2. Dimensional parameters for the analyses.

\begin{tabular}{cccccccc}
\hline $\boldsymbol{E}_{f}$ & $f_{f}$ & $\boldsymbol{E}_{\boldsymbol{m}}$ & $\boldsymbol{\sigma}_{\boldsymbol{c r}}$ & $\boldsymbol{t}_{\boldsymbol{f}}$ & $\boldsymbol{t}_{\boldsymbol{m o r}}$ & $\boldsymbol{E}_{\mathbf{1}}$ & $\boldsymbol{E}_{\mathbf{2}}$ \\
\hline$[\mathrm{GPa}]$ & {$[\mathrm{MPa}]$} & {$[\mathrm{MPa}]$} & {$[\mathrm{MPa}]$} & {$[\mathrm{mm}]$} & {$[\mathrm{mm}]$} & {$[\mathrm{GPa}]$} & {$[\mathrm{GPa}]$} \\
\hline 36 & 2150 & 1041 & 538 & 0.02 & 20 & 1077 & 27 \\
\hline
\end{tabular}

Figure 6 shows the linear and bilinear behavior according to the values listed in Table 1.

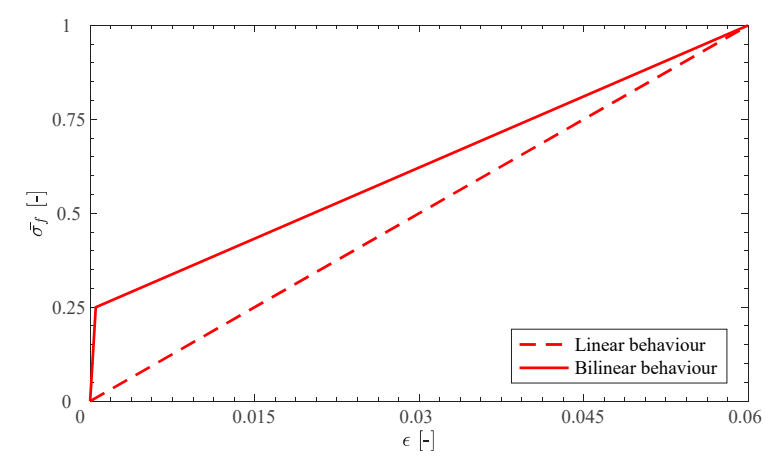

Figure 6. Stress-strain constitutive relationship of composite in tension, adopted for the analyses.

In order to have a good variability of the results, the mechanical compressed mortar matrix reinforcement the ratio $\left(\omega_{m}\right)$ and mechanical fiber reinforcement ratio $\left(\omega_{f}\right)$, which varied to define several $\mathrm{p}-\mathrm{m}$ interaction domains. In this way, the influence the constitutive relationship of other parameters, such as the mechanical reinforcement ratios, were analyzed. Figure 7 shows the numerical results in terms of $\mathrm{p}-\mathrm{m}$ interaction domains from case 1 to case 4 as the dimensionless parameters $\omega_{m}$ and $\omega_{f}$ change. The diagrams were grouped to fix the mechanical fiber reinforcement ratio, where $\omega_{f}$ was equal to $5 \%, 10 \%$, and $20 \%$ (Figure 7 a-c, respectively).

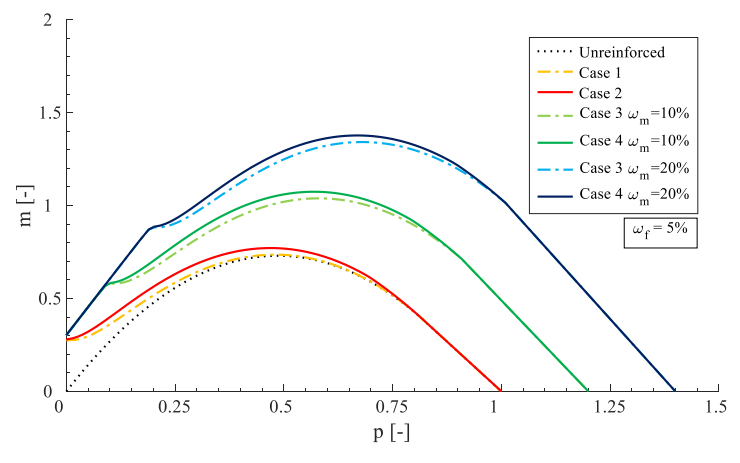

Figure 7. Cont. 


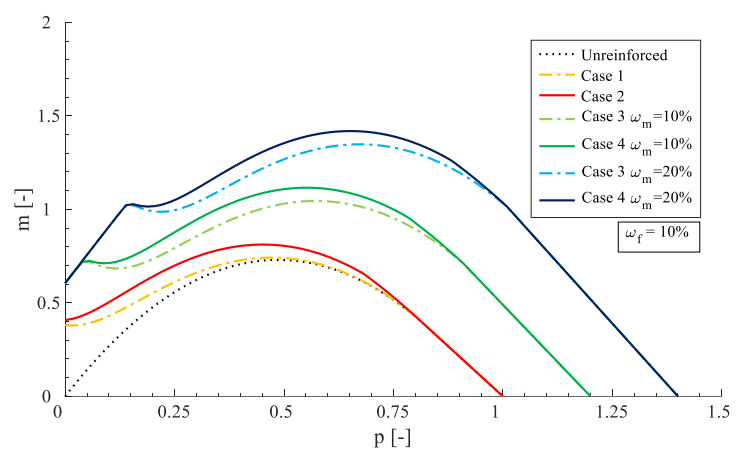

(b)

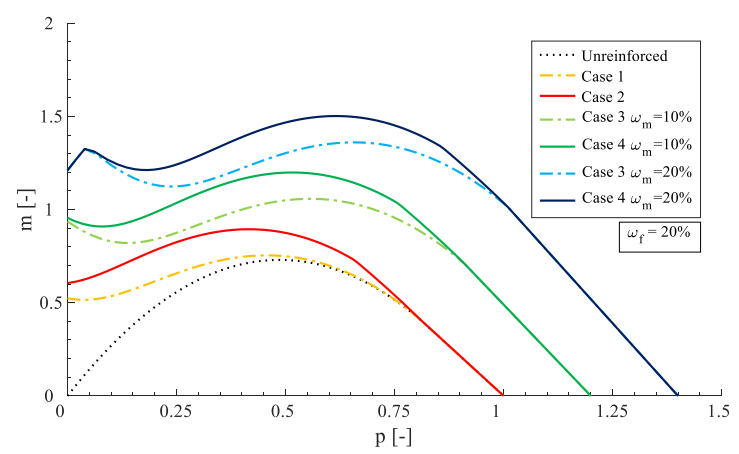

(c)

Figure 7. The $\mathrm{p}-\mathrm{m}$ interaction domains for all 4 cases: (a) $\omega_{f}$ is fixed $(5 \%)$; (b) $\omega_{f}$ is fixed $(10 \%) ;(\mathbf{c}) \omega_{f}$ is fixed $(20 \%)$.

In Figure 7, the comparison between the $\mathrm{p}-\mathrm{m}$ interaction domains at different mechanical ratios confirmed that the contribution of the mortar matrix played a non-negligible role, as its presence greatly enhanced the axial load capacity during compression and improved the bending capacity of the strengthened cross section. The increase in flexural capacity was mainly related to the mechanical fiber reinforcement ratio $\omega_{f}$. When $\omega_{f}$ was relatively low (for example the diagrams in Figure 7a), in the typical working range of masonry structures with a variable $\mathrm{p}$ from 0 to 0.4 , the increase in flexural capacity was relatively moderate if compared to the case where $\omega_{f}$ was higher. Moreover, results shown in Figure 7 confirmed that when the reinforcement ratios for the compression and tension sides were fixed, the different behavior of the stress-strain relationship of the composite, linear, or bilinear relationship provided a reserve of flexural capacity. Such reserve was greater the more $\omega_{f}$ increased. It is worth noting that when $\omega_{f}$ was smaller than $\omega_{m}$ (i.e., in case 4; Figure 7a), it an overlap of the p-m interaction domain at low compression forces can be observed. This is due to failure that occur on the tension side, where the composite material works at its ultimate strain and the influence of the different constitutive relationships is negligible. The failure on tension side tends to reduce when $\omega_{m}$ increases.

For higher axial force values, the $\mathrm{p}-\mathrm{m}$ interaction domain tends to overlap due to the fact that when the strengthened cross section is subjected to large axial forces, the FRCM on the tension side has a low working rate, favoring compressive behavior.

As mentioned before, increasing the flexural capacity of the masonry element is a limited benefit; in a seismic context, it is necessary to ensure that the element also has good performance in post-elastic fields in order to prevent collapse. It is possible to read such information from the bending moment-curvature diagrams (see Figure 8). 

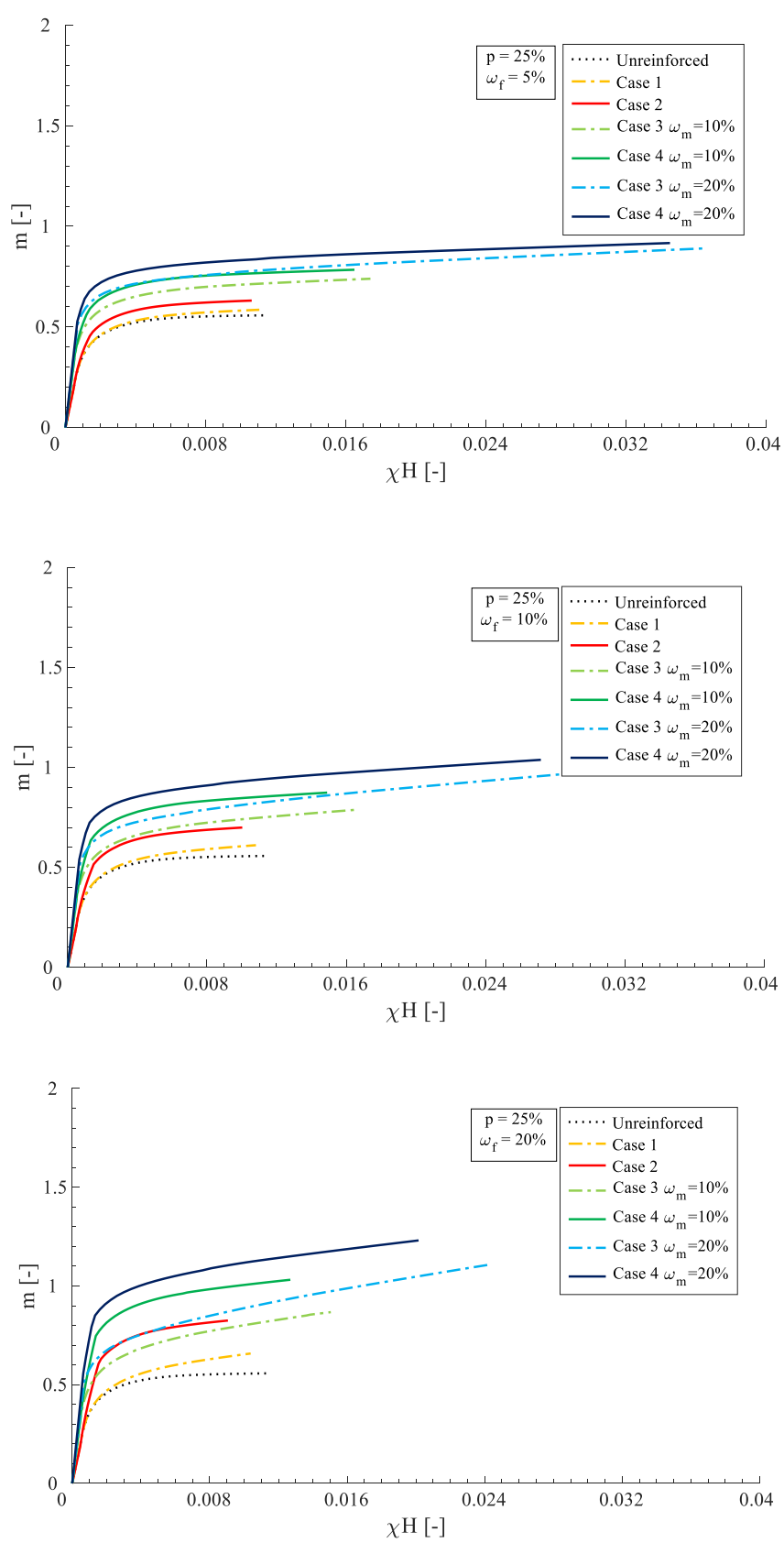

(c)

Figure 8. Bending moment-curvature diagrams for all 4 cases: (a) $\omega_{f}$ is fixed (5\%); (b) $\omega_{f}$ is fixed (10\%); (c) $\omega_{f}$ is fixed $(20 \%)$.

In Figure 8, it can be observed that the dimensionless curvature capacity $(\chi \mathrm{H})$ of the strengthened cross section was clearly affected by the different relationships between the composite materials. When observing cases 1 and 2, it is clear which matches case is reinforced on one side, and which strengthening system increases the flexural capacity reduces the ultimate curvature and ductility. In other words, applying reinforcement only on the tension side tends to weaken the cross section, even though it is related to an increase in flexural capacity. The presence of the mortar matrix in compression conversely causes an increase of flexural capacity and increases the ultimate curvature (see cases 3 and 4). How much curvature can be recovered from the mortar matrix is to the mechanical fiber reinforcement ratio $\omega_{f}$. As such, the higher $\omega_{f}$ is, the smaller the ultimate curvature is (see Figure 8), and thus the higher $\omega_{m}$ is needed to recover the lost curvature capacity. 
As observed in the $\mathrm{p}-\mathrm{m}$ interaction domains, the different relationships adopted for the composite material on the tension side provides different results in terms of ultimate curvature. In fact, a not already cracked mortar matrix (bilinear constitutive relationship) provides a greater result if compared to the one provided by the linear relationship. Such different behavior yields to a reduction in the ultimate curvature due to an increase in the neutral axis depth.

It is also interesting to observe how the ultimate curvature changes with the axial load for several specified cases (Figure 9). In cases where the strengthened cross section is characterized by a failure on the compression side-i.e., cases 1 and 2 (Figure 9a,b) - a continuous reduction of the ultimate curvature and ductility is observed. Conversely, initial increases of ultimate curvature, with the increase of the axial load in lower value ranges, are related to the cases with a failure on the tension side and the peak, with subsequent reduction representative of a transition, i.e., from "failure on tension side" to "failure on compression side".
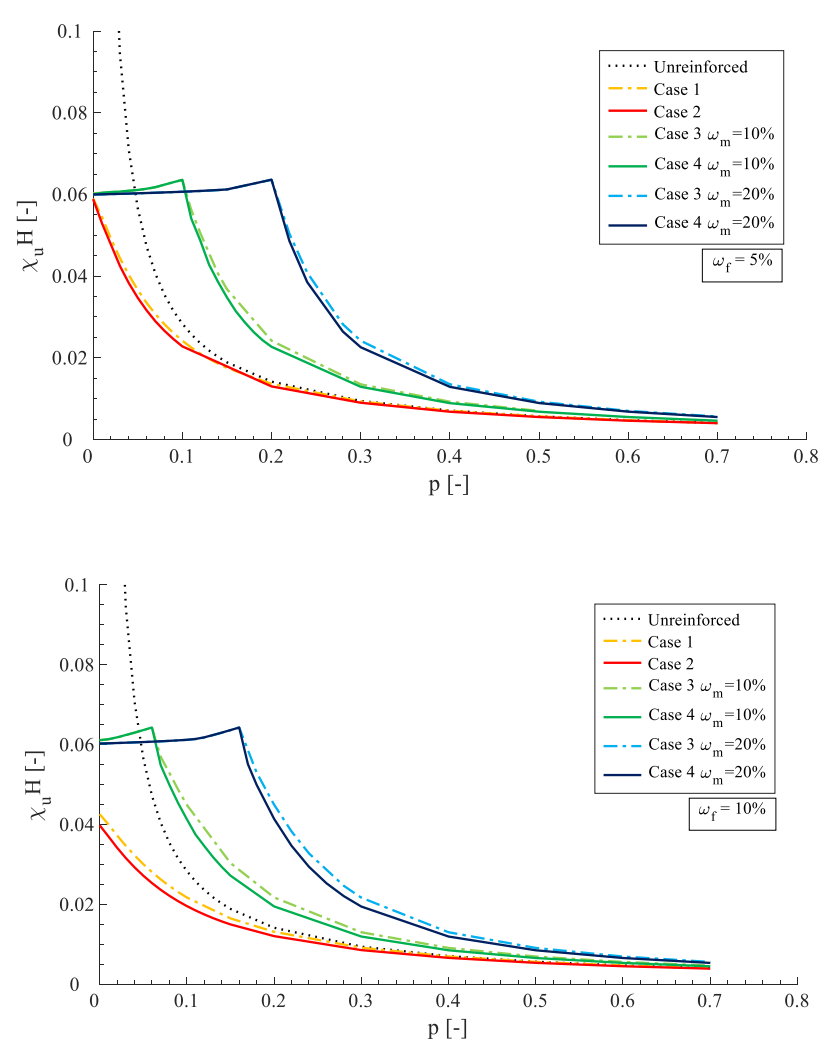

(b)

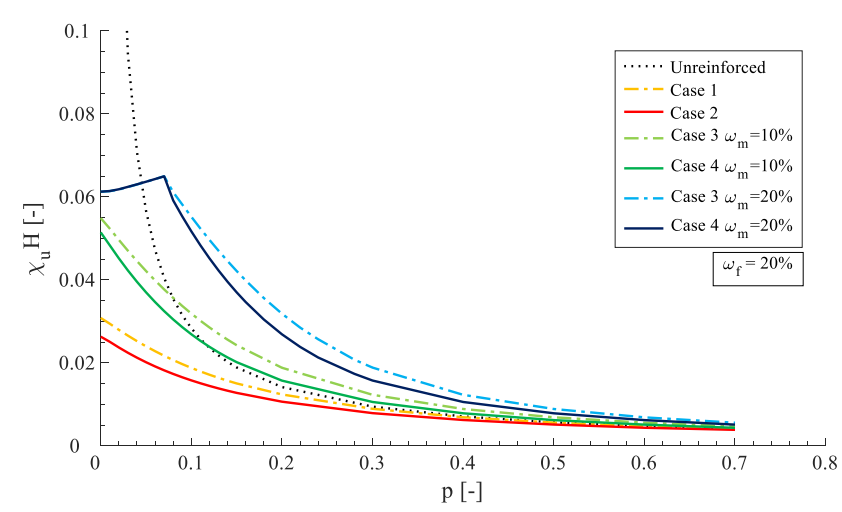

(c)

Figure 9. Axial load-ultimate curvature diagrams for all 4 cases: (a) $\omega_{f}$ is fixed (5\%); (b) $\omega_{f}$ is fixed $(10 \%) ;(\mathbf{c}) \omega_{f}$ is fixed $(20 \%)$. 
The analyses performed in the present work are based on a purely numerical approach. In order to validate the procedure proposed, we conducted a comparison with the specimens and materials experimentally tested by Papanicolaou et al. [38]. Based on the four previously defined cases, bending moment-curvature diagrams were evaluated according to experimental data, as shown in Figure 10. Tables 3 and 4 show the dimensional and dimensionless parameters from Papanicolaou et al. [38].

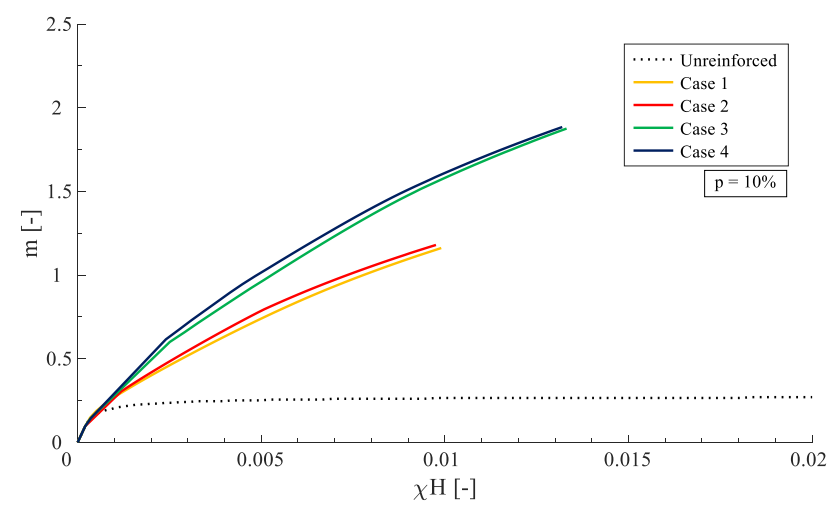

Figure 10. Numerical bending moment-curvature diagrams.

Table 3. Dimensional parameters, adapted from Papanicolaou et al. [38].

\begin{tabular}{cccccccc}
\hline \multicolumn{7}{c}{ Adopted Dimensional Parameters } \\
\hline$f_{c}$ & $f_{f}$ & $E_{m}$ & $\sigma_{c r}$ & $f_{\text {mor }}$ & $A_{f}$ & $E_{f}$ & $A_{\text {mor }}$ \\
\hline$[\mathrm{MPa}]$ & {$[\mathrm{MPa}]$} & {$[\mathrm{MPa}]$} & {$[\mathrm{MPa}]$} & {$[\mathrm{MPa}]$} & {$\left[\mathrm{mm}^{2}\right]$} & {$[\mathrm{GPa}]$} & {$\left[\mathrm{mm}^{2}\right]$} \\
\hline 4.3 & 3350 & 630 & 836 & 31.36 & 18.8 & 225 & 800 \\
\hline
\end{tabular}

Table 4. Dimensionless parameters, adapted from Papanicolaou et al. [38].

\begin{tabular}{ccccccc}
\hline \multicolumn{7}{c}{ Adopted Dimensionless Parameters } \\
\hline$E_{1} / f_{f}$ & $E_{2} / f_{f}$ & $\varepsilon_{c r}$ & $\varepsilon_{u f}$ & $\omega_{f}$ & $\omega_{m}$ & $\rho_{m}$ \\
\hline$[-]$ & {$[-]$} & {$[-]$} & {$[-]$} & {$[-]$} & {$[-]$} & {$[-]$} \\
\hline 75.2 & 64.9 & 0.003 & 0.01489 & 0.43 & 0.17 & 0.024 \\
\hline
\end{tabular}

Figure 10 shows the bending moment-curvature diagrams built with dimensionless parameters from Papanicolaou et al. [38]. Small increases occurred for cases 2 and 4, especially when compared to cases 1 and 3 . These increases depended on the adopted mechanical parameters, wherein the Young's modulus $E_{m}$ of the mortar matrix (630 MPa) was rather low, and the bilinear behavior was linear.

The comparison between numerical and experimental values is shown in Figure 11. It is worth noting that the cases 1 and 2 represent the cross section reinforced on both sides and on tensile side, respectively. Figure 11 does not highlight a clear and simple comparison, but, above all, it clarifies what this work has proposed. It is very clear that case 2 (i.e., cross section reinforced only on the tension side) has a significantly lower capacity compared to the experimental data. On the other hand, case 1 (i.e., cross section reinforced on both sides, in particular the case with axial load $p=0.10$ ) is in perfect agreement with the experimental value. Therefore, the presence of the mortar matrix in compression played a fundamental role in order not to excessively underestimate the flexural capacity of the strengthened masonry structural elements. 


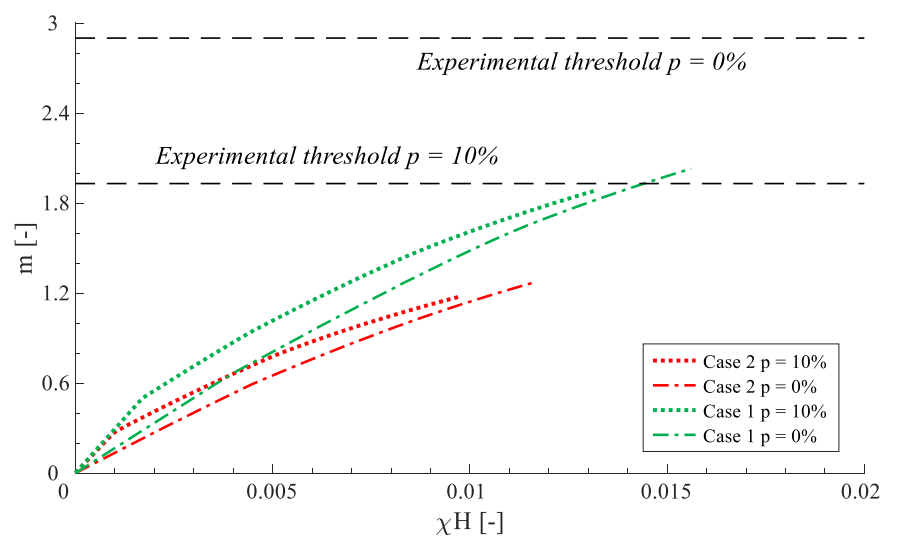

Figure 11. Comparison between numerical bending moment-curvature diagrams and experimental values.

It is worth underlining that the comparison was made with reference to a limited number of samples. Given the particular nature of the materials, the imperfect match with the experimental thresholds could be caused by experimental uncertainties during the test, which are not taken into account in the proposed numerical simulation. Certainly, the reliability of the model presented in this paper can be further validated by comparing the analytical results with further available experimental data.

\section{Conclusions}

The paper focused on the behavior of masonry cross sections strengthened with composite materials such as FRP or FRCM. The structural performance of strengthened cross section was evaluated via varying tensile behaviors in the composite and analyzing the contributions offered by the mortar matrix in the compression. As mentioned, this sought to remark upon the importance of considering the mortar matrices contributions vis-à-vis the tensile and compression sides to preventing excessive underestimation of the structural capacity. The presented results were in a dimensionless form and were valid for mechanical and geometric parameters, thus providing extremely useful results for the design and verification of strengthening interventions. The flexural capacity was evaluated in terms of $\mathrm{p}-\mathrm{m}$ interaction domains by changing the constitutive relationship of the FRCM. The strengthening system, even if only applied on the tensile side, provided clear benefits to the flexural capacity, causing a reduction in the ultimate curvature. Being able to preserve a plastic capacity reserve was useful for seismic behavior. For this reason, the contribution of the mortar matrix in compression played a major role. It was able to increase not only the flexural and axial capacity but also to provide a good recovery of the ultimate curvature and ductility, as was observed from bending moment-curvature diagrams. Moreover, the analysis of the axial load-ultimate curvature diagrams provided very useful results. It was possible to observe the trend of the ultimate curvature as the mechanical dimensionless parameters and the axial load change. The benefits offered from the mortar matrix in compression was clear in this study. Lastly, depending on the mechanical fiber reinforcement ratio, the ultimate curvature was almost always larger than the unreinforced cross section strengthened only on one side.

Author Contributions: Conceptualization, G.P.L. and A.P.; formal analysis and investigation, G.C. and G.R.; methodology, F.F. and G.P.L.; writing—original draft, G.C. and G.R.; writing—review and editing, F.F. and G.P.L.; supervision, A.P. All authors have read and agreed to the published version of the manuscript.

Funding: This research was funded by the Italian ReLUIS project (Italian Department of the Civil Protection-years 2019-2021).

Conflicts of Interest: The authors declare no conflict of interest 


\section{List of Symbols}

$f_{c} \quad$ compressive strength of masonry

$\varepsilon_{k} \quad$ conventional yielding strain of masonry in compression

$\varepsilon_{u} \quad$ conventional ultimate strain of masonry in compression

$\sigma_{c r} \quad$ first cracking in tension of the mortar matrix

$f_{f} \quad$ tensile strength of the composite

$\varepsilon_{c r} \quad$ strain corresponding to the stress $\sigma_{\mathrm{cr}}$

$\varepsilon_{u f} \quad$ ultimate strain of the composite

$f_{\text {mor }} \quad$ compressive strength of mortar matrix

$E_{C} \quad$ modulus of elasticity of the masonry

$E_{m} \quad$ modulus of elasticity of the mortar matrix

$E_{f} \quad$ modulus of elasticity of the dry fiber

$E_{1} \quad$ uncracked modulus of elasticity of the composite

$E_{2} \quad$ post- uncracked modulus of the composite system

$\bar{E}_{f} \quad$ normalized modulus of elasticity of the dry fiber

$\bar{E}_{1}$

$\bar{E}_{2}$

$\bar{\sigma}_{c r}$

$\bar{\sigma}_{f}$

$A_{m}$

$A_{f}$

$B$

H

P

normalized uncracked modulus of elasticity of the composite normalized post- uncracked modulus of elasticity of the composite normalized first cracking stress in tension of the mortar matrix normalized stress of the composite system cross section of mortar matrix cross section of dry fiber base of the cross section height of the cross section axial load normalized axial load $\mathrm{P}$ bending moment normalized bending moment $\mathrm{M}$ equivalent thickness of fibers thickness of mortar matrix lever arm of masonry resultant lever arm of FRCM resultant lever arm of mortar matrix resultant dimensionless factor that correlates real nonlinear stress distribution with stress block resultant dimensionless factor that correlates real distance of centroid of nonlinear stress distribution with the neutral axis depth depth of the neutral axis normalized neutral axis mechanical fiber reinforcement ratio mechanical compressed mortar matrix reinforcement ratio ratio between the thickness of the mortar matrix and the height of masonry cross section

\section{References}

1. Formisano, A. Theoretical and Numerical Seismic Analysis of Masonry Building Aggregates: Case Studies in San Pio Delle Camere (L'Aquila, Italy). J. Earthq. Eng. 2017, 21, 227-245. [CrossRef]

2. Chieffo, N.; Formisano, A. Induced seismic-site effects on the vulnerability assessment of a historical centre in the molise Region of Italy: Analysis method and real behaviour calibration based on 2002 earthquake. Geosciences 2020, 10, 21. [CrossRef]

3. Salzano, P.; Casapulla, C.; Ceroni, F.; Prota, A. Seismic Vulnerability and Simplified Safety Assessments of Masonry Churches in the Ischia Island (Italy) after the 2017 Earthquake. Int. J. Archit. Herit. 2020. [CrossRef]

4. Acito, M.; Magrinelli, E.; Milani, G.; Tiberti, S. Seismic vulnerability of masonry buildings: Numerical insight on damage causes for residential buildings by the 2016 central Italy seismic sequence and evaluation of strengthening techniques. J. Build. Eng. 2020, 28, 101081. [CrossRef] 
5. Alecci, V.; De Stefano, M.; Focacci, F.; Luciano, R.; Rovero, L.; Stipo, G. Strengthening masonry arches with lime-based mortar composite. Buildings 2017, 7, 49. [CrossRef]

6. Chieffo, N.; Formisano, A.; Miguel Ferreira, T. Damage scenario-based approach and retrofitting strategies for seismic risk mitigation: An application to the historical Centre of Sant'Antimo (Italy). Eur. J. Environ. Civ. Eng. 2019, 2116-7214. [CrossRef]

7. Task Group 9.3. Externally bonded FRP Reinforcement for RC Structures; Technical Report, fib Bulletin 14; International Federation for Structural Concrete: Lausanne, Switzerland, 2001.

8. Teng, J.G.; Chen, J.F.; Smith, S.T.; Lam, L. FRP Strength-Ened RC Structures; Wiley: London, UK, 2002.

9. Council of National Research (CNR). Guide for the Design and Construction of Externally Bonded FRP Systems for Strengthening Existing Structures-Materials, RC and PC Structures, Masonry Structures; CNR-DT 200 R1; CNR: Rome, Italy, 2013.

10. Council of National Research (CNR). Guidelines for the Design and Construction of Externally Bonded FRP Systems for Strengthening Existing Structures_Timber Structures; CNR-DT 201; CNR: Rome, Italy, 2005.

11. Council of National Research (CNR). Guidelines for the Design and Construction of Externally Bonded FRP Systems for Strengthening Existing Structures-Metallic structures; CNR-DT 202; CNR: Rome, Italy, 2005.

12. Salzano, P.; Bonati, A.; Ceroni, F.; Crisci, G.; Franco, A.; Occhiuzzi, A. Statistical analysis on mechanical properties of FRP materials for structural strengthening. In Proceedings of the 7th ECCOMAS Thematic Conference on Computational Methods in Structural Dynamics and Earthquake Engineering, Crete, Greece, 24-26 June 2019; Papadrakakis, M., Fragiadakis, M., Eds.; COMPDYN: Crete, Greece, 2019; pp. 5153-5168.

13. Nardone, F.; Lignola, G.P.; Prota, A.; Manfredi, G.; Nanni, A. Modeling of flexural behavior of RC beams strengthened with mechanically fastened FRP strips. Compos. Struct. 2011, 93, 1973-1985. [CrossRef]

14. Parisi, F.; Lignola, G.P.; Augenti, N.; Prota, A.; Manfredi, G. Rocking response assessment of in-plane laterally-loaded masonry walls with openings. Eng. Struct. 2013, 56, 1234-1248. [CrossRef]

15. Lignola, G.P.; Angiuli, R.; Prota, A.; Aiello, M.A. FRP confinement of masonry: Analytical modeling. Mater. Struct. 2014, 47, 2101-2115. [CrossRef]

16. Carozzi, F.G.; Bellini, A.; D’Antino, T.; de Felice, G.; Focacci, F.; Hojdys, L. Experimental investigation on tensile and shear bond properties of Carbon-FRCM composites applied on masonry substrates. Compos. Part $B$ 2016, 128, 100-119. [CrossRef]

17. Ramaglia, G.; Lignola, G.P.; Fabbrocino, F.; Prota, A. Impact of natural fibers on the ultimate behaviour of masonry elements. In Proceedings of the AIMETA 2017-Proceedings of the 23rd Conference of the Italian Association of Theoretical and Applied Mechanics, Salerno, Italy, 4-7 September 2017.

18. Kouris, L.A.S.; Triantafillou, T.C. State-of-the-art on strengthening of masonry structures with textile reinforced mortar (TRM). Constr. Build. Mater. 2018, 188, 1221-1233. [CrossRef]

19. Crisci, G.; Ceroni, F.; Lignola, G.P. Comparison between Design Formulations and Numerical Results for In-Plane FRCM-Strengthened Masonry Walls. Appl. Sci. 2020, 10, 4998. [CrossRef]

20. Garmendia, L.; San-José, J.T.; García, D.; Larrinaga, P. Rehabilitation of masonry arches with compatible advanced composite material. Constr. Build. Mater. 2011, 25, 4374-4385. [CrossRef]

21. Gattesco, N.; Boem, I. Experimental and analytical study to evaluate the effectiveness of an in-plane reinforcement for masonry walls using GFRP meshes. Constr. Build. Mater. 2015, 88, 91-104. [CrossRef]

22. Ramaglia, G.; Lignola, G.P.; Fabbrocino, F.; Prota, A. Numerical investigation of masonry strengthened with composites. Polymers 2018, 10, 334. [CrossRef]

23. Ramaglia, G.; Fabbrocino, F.; Lignola, G.P.; Prota, A. Unified Theory for Flexural Strengthening of Masonry with Composites. Materials 2019, 12, 680. [CrossRef]

24. Fabbrocino, F.; Ramaglia, G.; Lignola, G.P.; Prota, A. Ductility-based incremental analysis of curved masonry structures. Eng. Fail. Anal. 2019, 97, 653-675. [CrossRef]

25. D'Ambra, C.; Lignola, G.P.; Prota, A.; Sacco, E.; Fabbrocino, F. Experimental performance of FRCM retrofit on out-of-plane behaviour of clay brick walls. Compos. Part B Eng. 2018, 148, 198-206. [CrossRef]

26. Babaeidarabad, S.; De Caso, F.; Nanni, A. URM walls strengthened with fabric reinforced cementitious matrix composite subjected to diagonal compression. J. Compos. Constr. 2013, 18, 04013045. [CrossRef]

27. Ferretti, F.; Ferracuti, B.; Incerti, A.; Mazzotti, C. Diagonal Compression Tests on Masonry Panels Strengthened by FRP and FRCM. In Structural Analysis of Historical Constructions; Van Balen, K., Verstrynge, E., Eds.; CRC Press/Balkema: Boca Raton, FL, USA, 2016; pp. 1069-1076. 
28. Crisci, G.; Ceroni, F.; Lignola, G.P. Efficiency of FRCM Systems for Strengthening of Masonry Walls. In Proceedings of the 17th International Conference of Numerical Analysis and Applied Mathematics, Rhodes, Greece, 23-28 September 2019.

29. CNR-DT 215. Guide for the Design and Construction of Externally Bonded Fibre Reinforced Inorganic Matrix Systems for Strenghtening Existing Structures; Council of National Research: Rome, Italy, 2018.

30. Lignola, G.P.; Flora, A.; Manfredi, G. Simple method for the design of jet grouted umbrellas in tunneling. J. Geotech. Geoenviron. Eng. 2008, 134, 1778-1790. [CrossRef]

31. Lourenço, P.B. Experimental and Numerical Issues in the Modelling of the Mechanical Behaviour of Masonry; CIMNE: Barcelona, Spain, 1998.

32. CEN Eurocode 6-Design of Masonry Structures. In Part 1-1: General Rules for Reinforced and Unreinforced Masonry Structures; British Standards Institution: London, UK, 2005.

33. De Felice, G.; Aiello, M.A.; Caggegi, C.; Ceroni, F.; De Santis, S.; Garbin, E.; Gattesco, N.; Hojdys, Ł.; Krajewski, P.; Kwiecien, A.; et al. Recommendation of RILEM Technical Committee 250-CSM: Test method for Textile Reinforced Mortar to substrate bond characterization. Spring Mater. Struct. 2018, 51, 95. [CrossRef]

34. Bilotta, A.; Ceroni, F.; Nigro, E.; Pecce, M. Experimental tests on FRCM strengthening systems for tuff masonry elements. Constr. Build. Mater. 2017, 138, 114-133. [CrossRef]

35. Bilotta, A.; Ceroni, F.; Lignola, G.P.; Prota, A. Use of DIC technique for investigating the behavior of FRCM materials for strengthening masonry elements. Compos. Part B 2017, 129, 251-270. [CrossRef]

36. CEN Eurocode 2-Design of Concrete Structures-Part 1-1: General Rules and Rules for Buildings; British Standards Institution: London, UK, 2004.

37. Lignola, G.P.; Giamundo, V.; Prota, A.; Cosenza, E. A unified theory for RC cross sections up to ultimate load, including hardening or softening of concrete. In Proceedings of the 4th Fib Congress 2014, Mumbai, India, 10-14 February 2014; pp. 134-193.

38. Papanicolaou, C.G.; Triantafillou, T.C.; Papathanasiou, M.; Karlos, K. Textile reinforced mortar (TRM) versus FRP as strengthening material of URM walls: Out-of-plane cyclic loading. Mater. Struct. 2008, 41, 143-157. [CrossRef]

Publisher's Note: MDPI stays neutral with regard to jurisdictional claims in published maps and institutional affiliations.

(C) 2020 by the authors. Licensee MDPI, Basel, Switzerland. This article is an open access article distributed under the terms and conditions of the Creative Commons Attribution (CC BY) license (http://creativecommons.org/licenses/by/4.0/). 